\title{
Análise das notificações de intoxicações agudas, por agrotóxicos, em 38 municípios do estado do Paraná
}

\begin{abstract}
Analysis of notifications of acute intoxication, by agrochemicals, in 38 municipalities of the state of Paraná
\end{abstract}

Bruna Letícia Souza Taveira', Guilherme Souza Cavalcanti de Albuquerque ${ }^{2}$
1 Universidade Federal do Paraná (UFPR) - Curitiba (PR), Brasil. Orcid: https://orcid. org/0000-0001-51991594

brunataveira@outlook.com

2 Universidade Federal do Paraná (UFPR) - Curitiba (PR), Brasil.

Orcid: https://orcid. org/0000-0002-7544-

$412 X$

guilherme.albuquerque.

ufpr@gmail.com
DOI: $10.1590 / 0103-11042018 S 417$

RESUMO O Paraná é o segundo maior consumidor de agrotóxicos no Brasil, e sua notificação de intoxicações agudas não corresponde a esta realidade. Objetivou-se verificar a correlação entre consumo de agrotóxicos em municípios do Paraná e notificação de intoxicações agudas. Analisaram-se bancos de dados do consumo de agrotóxicos e da ocorrência de intoxicações. Foram realizadas entrevistas com agentes da vigilância epidemiológica, para compreender o processo de identificação e notificação dos casos. Não se evidenciou correlação entre consumo e notificação de intoxicação aguda. Concluiu-se que há subnotificação de intoxicações por agrotóxicos no Paraná, devida a fragilidades estruturais dos serviços de saúde.

PALAVRAS-CHAVE Agroquímicos. Envenenamento. Vigilância epidemiológica. Notificação.

ABSTRACT Paraná is the second largest consumer of agrochemicals in Brazil, and its notification of acute intoxications doesn't correspond to this reality. It was aimed to verify the correlation between the consumption of agrochemicals in the municipalities of Parana and the notification of acute intoxications. Databases were analyzed on the consumption of agrochemicals and occurrence of intoxications. Interviews with epidemiological surveillance agents were conducted, to understand the process of identification and notification of cases. There was no evidence of correlation between consumption and notification of acute intoxication. It was concluded that there is underreporting of agrochemicals intoxications in Paraná, due to structural fragilities in health services.

KEYWORDS Agrochemicals. Intoxication. Epidemiological surveillance. Notification. 


\section{Introdução}

O uso acentuado de venenos agrícolas data do período pós II Guerra Mundial, quando as indústrias fabricantes de armas químicas passaram a enxergar na agricultura um mercado potencial para seus produtos ${ }^{1}$. O Brasil, além de ser o país que mais consome agrotóxicos no mundo, em valores absolutos, desde 2008, também faz uso de cerca de 22 produtos proibidos na União Europeia e nos Estados Unidos da América, devido aos riscos que oferecem às saúdes humana e ambiental ${ }^{2}$. Entre os estados brasileiros, o Paraná é o segundo maior consumidor de agrotóxicos, alcançando cerca de $16 \%$ da quantidade total consumida no País, o equivalente a 48 mil toneladas ${ }^{3}$.

De acordo com a Organização Internacional do Trabalho (OIT)/Organização Mundial da Saúde (OMS), cerca de 70 mil trabalhadores de países em desenvolvimento morrem em decorrência de intoxicações agudas e crônicas por agrotóxicos. Outros 7 milhões são acometidos por doenças não fatais devidas aos pesticidas ${ }^{4}$.

A intoxicação por agrotóxicos pode ocorrer por via digestiva, respiratória, dérmica e/ou por contato ocular, ocasionando quadros agudos, subagudos ou crônicos. Entre os grupos mais afetados pelos danos causados pelos venenos agrícolas, destacam-se os trabalhadores da agricultura e da pecuária, que são expostos aos agrotóxicos desde o preparo do produto, por manipulação direta, até o armazenamento das embalagens após o uso'.

Um estudo realizado por Santos et al. ${ }^{\mathbf{5}}$ encontrou, como principais sintomas apresentados pelos agricultores após a exposição, tontura (presente em 22\% dos trabalhadores entrevistados), dor de cabeça (16\%), visão turva (11\%), náusea (11\%), diarreia (8\%), suor (8\%) e cólica abdominal (8\%). Como estes são sintomas muito inespecíficos, muitas vezes os agricultores não os correlacionam ao uso de agrotóxicos, o que contribui para a subnotificação dos casos².

Diversas são as dificuldades enfrentadas para estabelecer o diagnóstico de intoxicação aguda por agrotóxicos, entre as quais: baixa procura de atendimento médico, por parte dos agricultores; sintomas inespecíficos; pressão, por parte do agronegócio local, para ocultar o diagnóstico; falta de investigação clínica, por parte dos serviços de saúde etc $\mathbf{1}$.

Além do evidente dano para as saúdes humana e ambiental, as intoxicações agudas por agrotóxicos também causam prejuízo financeiro ao Estado, que desembolsa cerca de US\$ 1,28 no manejo das intoxicações, para cada dólar gasto na compra de agrotóxicos ${ }^{6}$.

Os casos de intoxicação por agrotóxicos podem ser notificados por diversos sistemas, entre os quais o Sistema Nacional de Informações Tóxico-Farmacológicas (Sinitox) e o Sistema de Informação de Agravos de Notificação (Sinan), este que, desde sua criação, em 1993, já apresentava carência de dados confiáveis para embasar práticas de saúde pública, mesmo após a criação do Sistema Único de Saúde (SUS). Em tese, o Sinan deve contemplar notificações dos mais diversos agravos, como acidentes de trabalho e violência doméstica, além de doenças infecciosas e não infecciosas ${ }^{4}$. Apesar de as intoxicações por agrotóxicos serem eventos de notificação compulsória, estimativas apontam que apenas $20 \%$ dos casos são, de fato, registrados ${ }^{2}$.

Todos os malefícios causados pelos agrotóxicos reforçam a necessidade não só do correto diagnóstico dos casos de intoxicação, como da notificação eficiente, propiciando o desenvolvimento de medidas de prevenção.

Diante do exposto, propôs-se a presente pesquisa, visando verificar a correlação entre o consumo de agrotóxicos em municípios do estado do Paraná e a notificação de intoxicações agudas por essas substâncias, além de conhecer o modo de realizar a identificação e a notificação dos casos nos serviços municipais de vigilância.

\section{Metodologia}

Trata-se de um estudo transversal, no qual, inicialmente, se realizou uma análise nos 
bancos de dados disponibilizados pelo Ministério da Saúde, através do Sinan, pelo Sistema de Monitoramento do Comércio e Uso de Agrotóxicos do Paraná (Siagro) e pelo Instituto Brasileiro de Geografia e Estatística (IBGE), além de uma avaliação da correlação entre o consumo de agrotóxicos e a ocorrência de intoxicação aguda por estes, em 38 municípios selecionados.

O estado do Paraná é dividido em 22 Regionais de Saúde (RS). Dentre elas, para compor a amostra, 3 foram escolhidas por serem compostas por municípios de pequeno e médio porte, com intensa atividade agrícola, o que totalizou 38 municípios.

Foram analisados dados fornecidos pelo Siagro, de consumo de agrotóxicos, em toneladas, no ano de 2015; o número de habitantes dos municípios, de acordo com estimativa realizada pelo IBGE para o ano de 2016; a área do estabelecimento agrícola de cada município, segundo o último censo agropecuário realizado pelo IBGE, em 2006; e o número de casos de intoxicação aguda por agrotóxicos agrícolas, domésticos e de saúde pública, por município, durante o ano de 2015, notificados no Sinan. A quantidade de agrotóxicos utilizada por hectare de estabelecimento agrícola foi comparada com o número de casos notificados no ano de 2015, para cada $100 \mathrm{mil}$ habitantes, visando verificar a existência de proporcionalidade. Foram excluídos os casos de intoxicação por raticidas.

Após a análise dos dados secundários, contatos telefônicos foram feitos para a realização das entrevistas em profundidade, semiestruturadas, com agentes da vigilância epidemiológica dos municípios, com o objetivo de compreender as ações e os fluxos de identificação e notificação dos casos de intoxicação aguda por agrotóxicos. Os números telefônicos das vigilâncias epidemiológicas de cada localidade foram obtidos através dos sites dos próprios municípios. Em relação àqueles cujos números de telefone da vigilância epidemiológica não constavam no site, procedeu-se contato telefônico com os gabinetes das prefeituras a fim de obtê-los. Buscou-se contato com a vigilância epidemiológica de todos os 38 municípios, dos quais 8 não deram retorno. Depois de estabelecida a comunicação entre as partes, a pesquisa foi apresentada aos trabalhadores, sendo-lhes enviados os respectivos Termos de Consentimento Livre e Esclarecido (TCLE) por e-mail. Aqueles que assim desejaram, devolveram os TCLE assinados, informando os dias e horários mais apropriados para a realização das entrevistas. Dos 30 municípios cujo contato inicial via telefone foi estabelecido com técnicos da vigilância epidemiológica, 29 aceitaram participar da pesquisa. As falas foram gravadas e posteriormente transcritas para análise. Das 29 entrevistas realizadas, 27 foram utilizadas na análise dos dados, correspondendo a $71 \%$ do número inicialmente proposto. Duas entrevistas foram descartadas, pois a qualidade do áudio não permitiu sua fidedigna transcrição.

Em cada um dos 27 municípios, um trabalhador da vigilância epidemiológica foi entrevistado, tendo sido indagado sobre tempo de serviço, treinamento sobre o assunto, dificuldades para realizar a notificação, existência de subnotificação, capacidade dos profissionais de saúde para diagnosticar os casos, possíveis melhorias no processo de identificação e notificação dos casos, e iniciativas dos municípios sobre o tema. Todas as entrevistas foram realizadas nas dependências do Núcleo de Estudos em Saúde Coletiva, localizado no Setor de Ciências da Saúde da Universidade Federal do Paraná, entre os meses de agosto de 2016 e fevereiro de 2017.

O projeto foi aprovado no Comitê de Ética em Pesquisa, sob o número 55157416.5.0000.0102.

Os municípios e as entrevistas foram codificados com números de 1 a 38 , a fim de garantir o sigilo e a privacidade dos participantes.

O projeto recebeu apoio financeiro da Fundação Araucária, no formato de bolsa-auxílio para iniciação científica. 


\section{Resultados}

\section{Consumo de agrotóxicos por município}

A análise dos bancos de dados mostrou que os municípios que figuraram como maiores consumidores de agrotóxicos no ano de 2015 não foram os que mais notificaram casos de intoxicação aguda por agrotóxicos no mesmo período, conforme apresentado no quadro 1 , que traz os municípios em ordem decrescente de consumo de agrotóxicos, em toneladas, por área de estabelecimento agrícola, e o número de casos de intoxicação notificados, por 100 mil habitantes.

Quadro 1. Consumo de agrotóxicos em toneladas por hectare e casos de intoxicação aguda por agrotóxicos por município para cada 100 mil habitantes notificados no ano de 2015.

\begin{tabular}{|c|c|c|c|c|c|}
\hline Município & Consumo $^{1}$ & Casos $^{2}$ & Município & Consumo $^{1}$ & Casos $^{2}$ \\
\hline 29 & 19,47 & 0 & 3 & 4,49 & 105,24 \\
\hline 15 & 19,01 & 0 & 26 & 4,46 & 26,38 \\
\hline 13 & 14,05 & 6,29 & 24 & 3,99 & 0 \\
\hline 4 & 7,9 & 0 & 18 & 3,63 & 12,7 \\
\hline 9 & 7,7 & 0 & 31 & 3,56 & 17,22 \\
\hline 7 & 7,56 & 9,56 & 25 & 3,21 & 9,64 \\
\hline 14 & 7,39 & 6,7 & 8 & 3,06 & 33,09 \\
\hline 2 & 7,39 & 29,97 & 6 & 2,09 & 7,29 \\
\hline 12 & 7,06 & 9,99 & 28 & 1,97 & 22,04 \\
\hline 1 & 6,85 & 0 & 20 & 1,64 & 16,74 \\
\hline 38 & 6,73 & 0 & 19 & 1,19 & 62,16 \\
\hline 10 & 6,68 & 0 & 21 & 1,09 & 6,98 \\
\hline 11 & 6,2 & 0 & 17 & 1,01 & 0 \\
\hline 36 & 6,05 & 0 & 37 & 1 & 0 \\
\hline 16 & 5,66 & 54,6 & 33 & 0,55 & 0 \\
\hline 24 & 5,25 & 14,77 & 32 & 0,5 & 6,06 \\
\hline 22 & 5,24 & 28,35 & 30 & 0,46 & 1,77 \\
\hline 35 & 4,79 & 3,1 & 34 & 0,25 & 0 \\
\hline 23 & 4,67 & 0 & 5 & 0,24 & 0 \\
\hline
\end{tabular}

Fonte: Elaboração própria baseada em dados do IBGE, Siagro e Sinan.

1 Em toneladas por hectare multiplicado por 1000 [(ton/ha)x103].

2Número de casos notificados no ano de 2015 para cada 100 mil habitantes (casos/100 mil habitantes). 
Os valores médio, máximo e mínimo de consumo de agrotóxicos foram bastante variados, conforme mostrado no quadro 1 . O mesmo ocorreu com os casos de intoxicação aguda por agrotóxicos notificados no Sinan, também demonstrados no quadro 1 . O mínimo de zero casos notificados foi obtido por 16 municípios, codificados pelos números $2,5,9,10,12,14,15$, 16, 17, 22, 23, 27, 29, 33, 34 e 38. Já a média de intoxicação aguda por agrotóxicos notificada no Sinan foi de 12,91 casos/100 mil habitantes, com o máximo de 105,24 casos notificados pelo município 3 e o mínimo de 0 casos notificados pelos municípios citados acima.

O município 3, que despontou com o maior número de casos notificados, por 100 mil habitantes, economicamente destacou-se por uma intensa atividade agrícola e de fumicultura. $\mathrm{O}$ técnico da vigilância epidemiológica entrevistado, que conhecia o fluxo de notificação das intoxicações agudas por agrotóxicos, não referiu dificuldades para manusear o Sinan, acreditando que os médicos estavam capacitados para diagnosticar as intoxicações. Para ele, houve uma subnotificação das intoxicações agudas por agrotóxicos, pois entendia que existiram mais casos por ano do que aqueles de fato notificados em seu município.

Entre os 16 municípios sem casos notificados no ano de 2015, foram entrevistados servidores de 11. Naquele universo, a agropecuária figurava como a principal atividade econômica em oito municípios (73\%), e a prestação de serviços, no restante (27\%). Dos entrevistados dessas localidades, $73 \%(n=8)$ trabalhavam na vigilância epidemiológica havia nove anos ou menos; $91 \%(\mathrm{n}=10)$ afirmaram conhecer o fluxo das notificações; $55 \%$ ( $n=6$ ) não recebiam treinamento havia mais de cinco anos ou trabalhavam havia menos de cinco anos na vigilância epidemiológica e, até o momento, não tinham recebido nenhum treinamento sobre o assunto; $73 \%(\mathrm{n}=8)$ deles acreditavam que havia subnotificação das intoxicações agudas por agrotóxicos; $91 \%(\mathrm{n}=11)$ pensavam que algo diferente deveria ser feito para melhorar a identificação e a notificação dos casos; e 55\% $(\mathrm{n}=6)$ acreditavam que os médicos estavam capacitados para realizar o diagnóstico das intoxicações agudas por agrotóxicos. Tais dados apontam para uma possível falta de capacitação, tanto por parte dos médicos, para realizarem o diagnóstico, quanto por parte dos técnicos da vigilância epidemiológica, para conduzirem as notificações.

\section{Ac̣ões das vigilâncias epidemiológicas}

Quando questionados sobre o tempo de trabalho, pouco menos da metade dos entrevistados (44,4\%) informou que trabalhava havia 4 anos ou menos na vigilância epidemiológica; $33,3 \%$, entre 5 e 9 anos; 7,4\%, entre 10 e 14 anos; 3,7\%, entre 15 e 19 anos; e 11,1\%, havia 20 anos ou mais.

Todos os entrevistados afirmaram ter conhecimento do fluxo das notificações de intoxicações agudas por agrotóxicos. Entretanto, apenas $63 \%$ (17 entrevistados) afirmaram saber aproximadamente o montante de casos notificados anualmente por seus municípios. Mesmos assim, quando confrontados os números estimados com os efetivamente notificados, apenas $12 \%(n=2)$ dos entrevistados informaram um número aproximadamente correto (número de intoxicações registrados \pm dois casos/ano). Os demais informaram um número muito acima da quantidade de casos notificados, mostrando que, na sua percepção cotidiana, havia mais casos de intoxicação aguda por agrotóxicos do que aqueles registrados no Sinan, conforme demonstrado pelo gráfico 1 . O fato de terem recebido treinamento nos últimos cinco anos e o tempo de trabalho na vigilância epidemiológica não foram relevantes na aproximação da percepção de casos com a quantidade notificada, uma vez que, entre aqueles que receberam treinamento, apenas $8 \%(\mathrm{n}=1)$ perceberam casos quantitativamente aproximados ao número de notificações, contra os $7 \%(n=1)$ daqueles que não receberam treinamento. $\mathrm{O}$ mesmo ocorreu entre aqueles que trabalhavam havia mais de cinco anos na vigilância epidemiológica: a percepção dos 
casos se aproximou do número de casos notificados para $7 \%(\mathrm{n}=1)$ deles, contra os $8 \%(\mathrm{n}=1)$ dos que trabalhavam havia menos tempo. Entretanto, não se pode afirmar que ter mais qualificação e experiência não foi importante, devido ao número muito pequeno de participantes que se aproximaram da quantidade notificada de casos, o que impediu maiores generalizações.

Gráfico1. Percepção casos de intoxicação aguda por agrotóxicos e número de casos notificados no Sinan

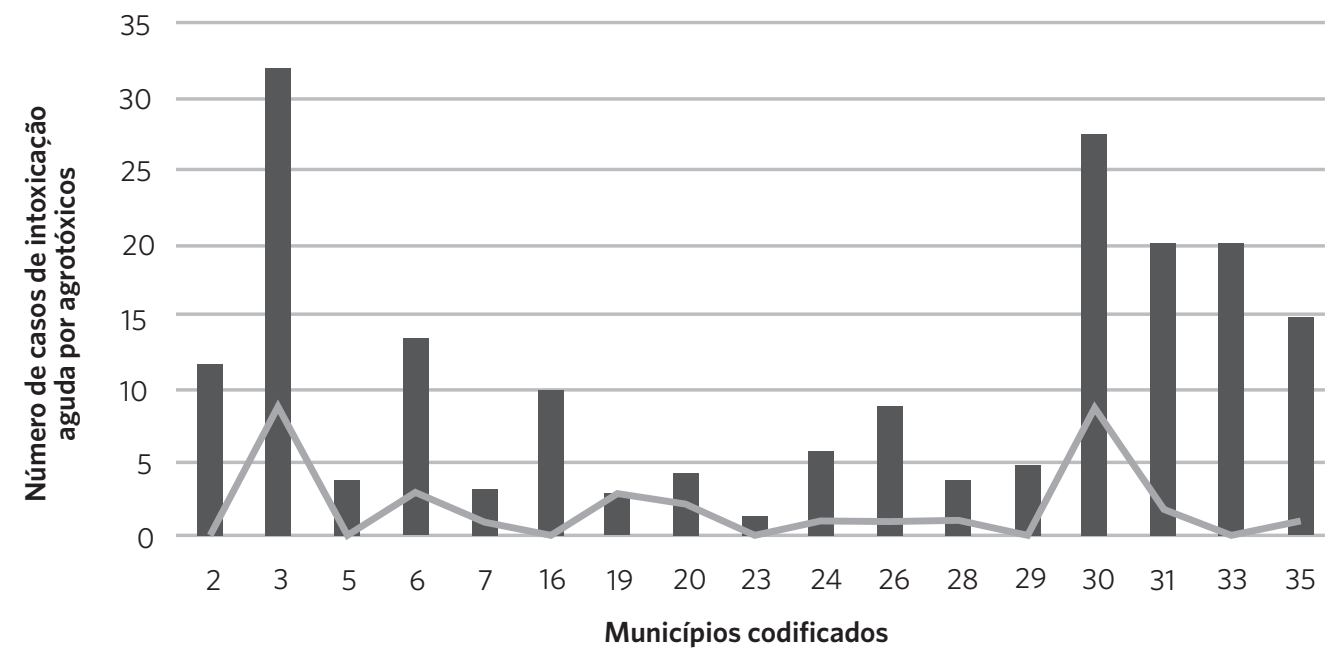

Percepção de casos $\quad$ Casos notificados

Fonte: Elaboração própria.

Nota: No eixo $X$, as cidades analisadas e codificadas por números. No eixo $Y$, as barras representam a percepção dos trabalhadores quanto ao número de casos de intoxicação aguda notificados; as linhas representam o número total real de casos notificados no ano de 2015.

Com relação a treinamento sobre o assunto, $48,1 \%(n=13)$ alegaram ter recebido algum nos últimos cinco anos. Outros 33,3\% ( $\mathrm{n}=9)$ relataram não ter recebido treinamento em cinco anos, e os demais $18,5 \%(n=5)$ estavam havia menos de cinco anos no serviço, mas não receberam qualquer tipo de treinamento sobre o assunto, o que totalizou $51,9 \%$ dos entrevistados trabalhando sem treinamento sobre intoxicações agudas por agrotóxicos.

O levantamento da percepção de subnotificação dos casos de intoxicação aguda por agrotóxicos, por parte dos trabalhadores da vigilância epidemiológica, mostrou que 81,5\% deles (22 entrevistados) acreditavam que o número de casos era subestimado. Entre as causas apontadas por eles, destacava-se a baixa procura, por parte da população exposta, citada por $45,45 \%$ $(n=10)$ daqueles que acreditavam haver subnotificação; a falha no diagnóstico, por parte dos médicos, foi apontada por 40,91\% (n=9); e a não notificação dos casos diagnosticados foi citada por $31,82 \%(n=7)$ dos entrevistados, conforme demonstrado no gráfico 2. 
Gráfico 2. Motivos elencados pelos entrevistados que acreditam haver subnotificação dos casos de intoxicação aguda por agrotóxicos

Causas para subnotificação

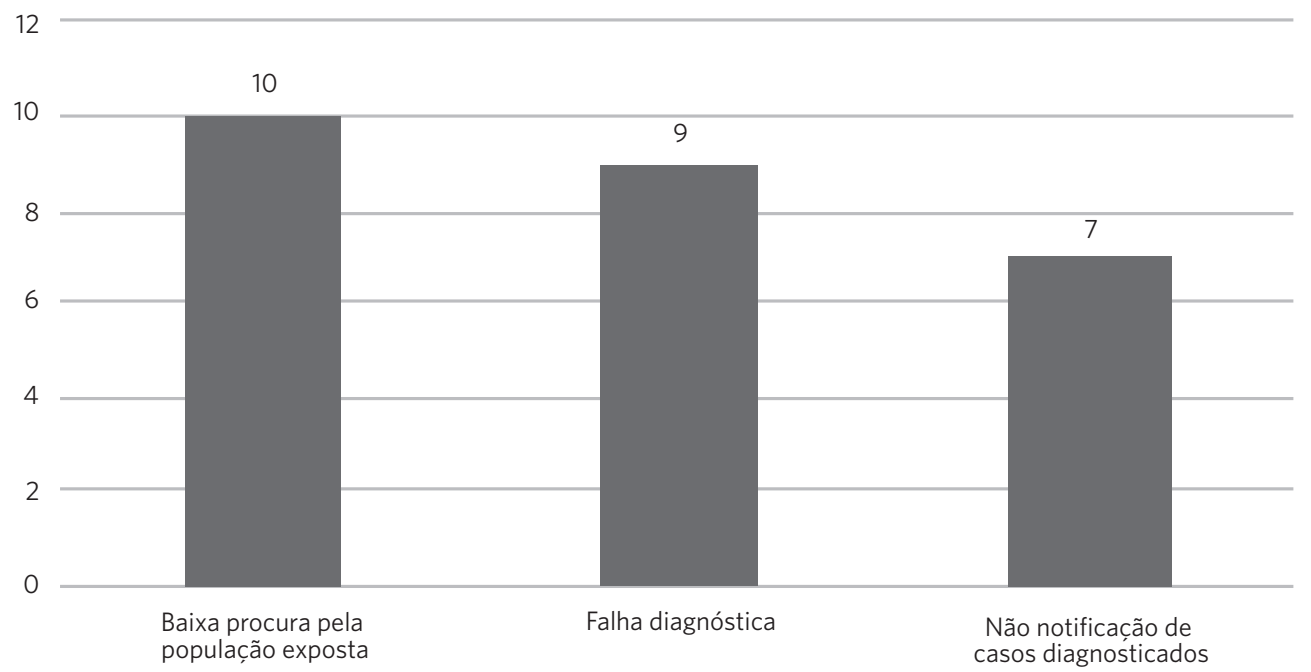

Fonte: Elaboração própria.

Nota: No eixo $\mathrm{X}$, os principais motivos citados. No eixo $\mathrm{Y}$, o número de profissionais que apontou cada um dos motivos.

Como motivos para a baixa procura do serviço de saúde, por parte da população exposta, citou-se a recorrência dos sintomas, que fez com que os pacientes se habituassem a tais manifestações clínicas quando usavam os agrotóxicos; o receio de admitir falhas no uso dos Equipamentos de Proteção Individual (EPI); e o medo de represálias, por parte do agronegócio local, uma vez que, se estabelecida a relação entre a intoxicação por agrotóxicos e a atividade laboral, a vigilância sanitária deveria ser acionada para vistoriar o local de trabalho à procura de irregularidades. Tais motivos podem ser exemplificados pelas falas a seguir:

Acho que por medo de procurar ajuda ou, às vezes, o paciente não conta, também. Pode ser por medo de represália dos patrões, porque trabalha em firma... Tudo isso. (Entrevista 4).

[...] a gente sabe que muitos acabam ficando em casa, tratando, com alguns conhecimentos empíricos, trabalhar com isso. Na verdade, eles não querem ir no hospital mesmo, ou na unidade de saúde, porque já sabem que é do produto que eles usam no plantio mesmo, principalmente do fumo. É isso que eu sinto, pelo menos, quando a gente pergunta por que que não veio antes. (Entrevista 6).

A falha no diagnóstico das intoxicações agudas por agrotóxicos, por parte dos médicos, é tida como consequência de uma anamnese superficial, focada apenas na resolução dos sintomas, sem se importar com as causas; da alta rotatividade dos profissionais, que, muitas vezes, atuam por pouco tempo no município, de maneira que os treinamentos se perdem rapidamente com a troca dos médicos; e das lacunas na qualificação dos próprios médicos, que acabam por não saber como diagnosticar as intoxicações agudas por agrotóxicos, como apontam trechos das entrevistas abaixo:

Eu acho que tem uma falha bem grande no diagnóstico, de perguntar pro paciente o que está 
acontecendo, com o que ele teve contato. (Entrevista 2).

A população não procura. Se ele tem um certo sintoma, $[. .$.$] não conta pro médico ou é mal in-$ terpretado; não consegue expor, de verdade; não é investigado. (Entrevista 20).

Já a falha das notificações, mesmo na vigência do diagnóstico, é vista como decorrente da alta demanda de atendimentos, tanto por parte dos médicos quanto pela equipe de enfermagem; e pela baixa importância dada à notificação pelos profissionais, o que também recai sobre a alta rotatividade, uma vez que demanda tempo e treinamento para que estes compreendam a necessidade de sempre notificar os casos. Por outro lado, quando a capacitação surte efeito, muitas vezes o contrato de trabalho é encerrado, conforme explícito nos trechos das seguintes entrevistas:

O profissional, às vezes, não preenche. Não por não saber, mas por falta de tempo. E os casos que não chegam até a gente, pela falta de procura. (Entrevista 36).

No hospital, mesmo, a gente vê que tomou alguma coisa, mas não é notificado. Por exemplo, assim: lá eu trabalho no PS [pronto socorro], e tem uma quantidade muito grande de pacientes, e você acaba não notificando no momento. O paciente ganha alta e você acaba não notificando. (Entrevista 11).

O primeiro problema é a rotatividade de profissionais, e o segundo problema é a falta de comprometimento do profissional. Porque eles sabem que têm que notificar, que é importante, mas eles não notificam. Isso não é só para agrotóxicos, é para outras situações também. (Entrevista 22).

Quando indagados sobre a presença de alguma iniciativa, por parte do município, para melhorar a identificação e a notificação dos casos de intoxicação aguda por agrotóxicos, $55,6 \%(\mathrm{n}=15)$ dos participantes alegaram não haver ou desconhecer.
Entre os 12 entrevistados que responderam haver iniciativa, por parte do município, a maioria das respostas versou sobre ações genéricas realizadas pelos próprios servidores, que consistiam em orientações entre eles mesmos e para os agricultores que procuravam $o$ atendimento, feitas de maneira informal, esporádica e assistemática.

Apenas dois entrevistados apontaram ações realmente organizadas pelo município, tais como: orientação em todas as comunidades agrícolas da localidade; reunião com os Agentes Comunitários de Saúde e determinação de que passassem de casa em casa, conversando com os moradores sobre o assunto; orientação para os médicos e enfermeiros da atenção primária; e até mesmo avisos na rádio local sobre $\mathrm{o}$ assunto.

Quando indagados sobre possíveis dificuldades no manuseio do sistema eletrônico para notificação dos casos no Sinan, apenas dois servidores (7,4\%) alegaram enfrentar problemas, sendo que um deles $(3,7 \%)$ nunca notificou casos de intoxicação aguda por agrotóxicos. Os demais (88,9\%), no entanto, não relataram qualquer dificuldade operacional com o sistema.

Quase metade dos entrevistados, 48,1\% ( $n=13)$, entenderam que os médicos dos seus municípios não estavam capacitados para realizar adequadamente o diagnóstico das intoxicações agudas por agrotóxicos, fosse por desconhecimento técnico - 79\% (n=11) - ou pela realização de anamneses superficiais, diante do ritmo de atendimento imposto nos serviços $-29 \%(n=4)$. As entrevistas abaixo exemplificam os apontamentos realizados:

A maioria não sabe. Sente aquela dificuldade e acaba tratando outra coisa, e não o que deveria. Falta informação, sabe? Mas não todos. (Entrevista 28).

Às vezes, por falta de tempo, de interesse, acabam não dando importância. (Entrevista 36).

[...] o diagnóstico também é falho. O que está em 
alta hoje é dengue; nós temos muita retrovirose na nossa regional. Então, o pessoal se atenta muito no que tem no momento e acaba esquecendo no que pode ter além. Inclusive, tivemos um paciente, há pouco tempo, que, desde o começo, batemos de frente com o médico, até que ele resolveu fazer os exames para confirmar a intoxicação. (Entrevista 30).

Uma quantidade expressiva de participantes $(85,2 \%)$ afirma que mudanças precisam ser feitas para melhorar a identificação e notificação dos casos de intoxicação aguda por agrotóxicos. As principais mudanças sugeridas foram: treinamento para os médicos (57\% dos entrevistados); conscientização da população (30\%); treinamento para os técnicos das vigilâncias epidemiológica e sanitária (35\%); e maior controle do comércio de venenos agrícolas (13\%). Com relação à conscientização da população, sugeriram que seja voltada para o manejo dos agrotóxicos, o descarte correto das embalagens, a procura por atendimento médico em caso de sintomas e a utilização dos EPI. Foi levantada, ainda, a possibilidade de trabalhar nas escolas para conscientizar as crianças, tornando-as agentes de educação para os pais, bem como de utilizar mídias locais para que o assunto chegue até a população.

\section{Discussão}

A média de casos de intoxicação aguda por agrotóxicos notificados nos municípios pesquisados, no ano de 2015 - 12,91 casos/100 mil habitantes -, foi superior àquela encontrada por Lara et al. ${ }^{7}$ durante o período compreendido entre 2006 e 2010, para o estado do Paraná, que foi de 8,5 a 11,3 casos registrados a cada 100 mil habitantes. Por sua vez, os resultados de Lara et al. ${ }^{7}$ foram superiores aos encontrados por Faria, Fassa e Facchini ${ }^{4}$, no período entre 2001 e 2005, de 5,6 casos registrados a cada 100 mil habitantes, no estado. Haja vista o evidente aumento do consumo de agrotóxicos no decorrer desse período, inclusive com o Brasil alcançando a marca de maior consumidor de agrotóxicos desde 2008 , tais dados sugerem um aumento na incidência de intoxicação aguda por agrotóxicos. Não se exclui, no entanto, a possibilidade de tal resultado ser decorrente de melhorias na identificação e notificação dos casos, hipótese reforçada pelo fato de que a notificação das intoxicações agudas por agrotóxicos apenas tornou-se obrigatória pela Portaria ${ }^{0} 104$, de 25 de janeiro de $2011^{8}$, ou, ainda, devido ao fato de os municípios analisados na pesquisa terem maior incidência de casos do que os demais municípios do Paraná.

O fato de que a maioria dos entrevistados que afirmaram conhecer o número aproximado de casos de intoxicação aguda por agrotóxicos terem dito números acima daqueles registrados no Sinan, associado à percepção, por parte de 81,5\% dos entrevistados, de que o número de casos de intoxicação aguda por agrotóxicos é subestimado, contribui para a hipótese de subnotificação dos casos. Essa subnotificação também foi aventada por Silva et al.9, que encontraram um número de intoxicações aquém do esperado para o consumo de agrotóxicos em São Miguel do Oeste (SC). Menck ${ }^{\mathbf{1 0}}$ também apontou subnotificação de casos, uma vez que a maioria das intoxicações registradas tem o meio urbano como local de ocorrência, quando $85 \%$ dos agrotóxicos são consumidos nas áreas rurais.

Os motivos apontados no presente estudo como causas para a subnotificação - baixa procura, por parte da população, por atendimento médico; falha no diagnóstico; e não notificação dos casos diagnosticados - também foram verificados em outros trabalhos"

A falha diagnóstica por falta de conhecimento médico e o não reconhecimento da importância de notificar as intoxicações por agrotóxicos foram averiguadas por Rebelo et al. ${ }^{12}$ ao compararem os óbitos apontados em diversas fontes de notificação. Um estudo realizado por Santos ${ }^{\mathbf{1 3}}$ também aponta a baixa qualificação dos médicos para atuarem na saúde do trabalhador como causa para o baixo diagnóstico das intoxicações. 
Em seu estudo, Bedor et al. ${ }^{14}$ mostram que, apesar de 30\% dos trabalhadores rurais entrevistados terem apresentado sintomas de intoxicação aguda em algum momento durante a aplicação de agrotóxicos, apenas $7 \%$ foram diagnosticados com intoxicação aguda por agrotóxicos devida à baixa procura e à falha no diagnóstico. Em análise semelhante, Santos ${ }^{13}$ averiguou que $85,7 \%$ dos agricultores referiram sintomas de intoxicação após a exposição aos agrotóxicos em algum momento da vida, mas apenas dois deles procuraram atendimento médico.

As mudanças sugeridas pelos entrevistados para melhorar a prevenção, identificação e notificação dos casos de intoxicação aguda por agrotóxicos, como treinamento para os profissionais de saúde (médicos e outros técnicos das vigilâncias epidemiológica e sanitária), conscientização da população e maior controle do comércio de venenos agrícolas também foram levantadas por outros estudos, como o de Santana, Moura e Nogueira ${ }^{15}$, que recomendam que os profissionais de saúde recebam treinamento para identificar e tratar corretamente os casos de intoxicação aguda por agrotóxicos, além de realizar a vigilância à saúde com especial atenção para a prevenção e o controle dos casos, e a conscientização da população para o manuseio seguro dos agrotóxicos como medida necessária para a prevenção imediata dos agravos decorrentes do uso desses produtos.

Em seu trabalho, Santos ${ }^{13}$ observou o uso indiscriminado de agrotóxicos sem indicações ou orientações feitas por profissionais. Evidenciou que $100 \%$ da população estudada faziam uso de agrotóxicos, mas menos da metade (47,8\%) recebia orientação técnica e apenas $28,5 \%$ utilizavam receituário agronômico. Além disso, pouco mais da metade $(52,3 \%)$ dos trabalhadores entrevistados afirmou utilizar EPI.

O estudo de Malaspina, Zinilise e Bueno' ${ }^{16}$ sugere que sejam promovidas ações integrais de proteção e promoção à saúde, fortalecimento da atenção básica e especializada para a realização de diagnóstico e tratamento, acompanhamento e monitoramento da população exposta aos agrotóxicos, além de conscientização e educação da comunidade sobre os riscos da exposição e intoxicação por agrotóxicos, reconhecendo, assim como no presente estudo, a necessidade de melhorar tais aspectos do cuidado à saúde. Os autores ainda apontam como necessária para o sucesso de tais ações a articulação entre os vários ministérios, como o da Saúde, da Agricultura e do Meio Ambiente, com o envolvimento de todas as esferas de governo - federal, estadual e municipal.

A utilização de mídias locais, sugerida por um dos entrevistados da presente pesquisa, também foi apontada como possível fator de melhoria por Santos ${ }^{17}$, que propõem a elaboração e divulgação de material informativo sobre os malefícios dos agrotóxicos.

Também para melhorar as notificações de agravos de notificação compulsória, Carneiro et al. ${ }^{18}$ apontam a busca ativa como possível medida. Já Santos" refere a necessidade de capacitação dos profissionais responsáveis pelas notificações como forma de minimizar as subnotificações. Em seu estudo, Goto ${ }^{19}$ cita ambas as mudanças - busca ativa e qualificação dos profissionais - como necessárias para o aprimoramento das notificações no Sinan.

Em seu estudo, Bordoni et al. ${ }^{20}$ citam o método de captura-recaptura, que consiste no cruzamento de dados comuns e exclusivos de diferentes bancos de dados, como forma de mensurar o número de casos subestimados.

Chama atenção o fato de que, no presente estudo, a busca ativa não foi sequer mencionada. A falta de estrutura e de pessoal nas vigilâncias municipais talvez explique o rechaço a esta ideia.

\section{Conclusões}

O presente estudo não evidencia uma correlação positiva entre maior consumo de agrotóxicos e maiores taxas de intoxicação aguda por agrotóxicos nos municípios analisados, entretanto, os resultados apontam para a ocorrência de subnotificação de casos, motivo pelo qual não se pode afirmar que a 
quantidade consumida de agrotóxicos não esteja relacionada com maiores ocorrências de intoxicação aguda por agrotóxicos, como era de se esperar.

Os apontamentos realizados pelos técnicos das vigilâncias epidemiológicas entrevistados evidenciam a necessidade de melhorar a identificação, notificação e prevenção dos casos de intoxicação aguda por agrotóxicos, por meio de treinamento e capacitação dos médicos e demais profissionais de saúde envolvidos, além da conscientização da população, bem como a melhoria da estrutura das vigilâncias dos municípios.

O estudo deixa clara a necessidade de um sistema de informação que garanta a qualidade de coleta, armazenamento, sistematização e disponibilização das informações em bancos de dados que reflitam a realidade da população brasileira e que possam ser usados de maneira confiável para direcionar as medidas de saúde pública.

\section{Referências}

1. Londres, F. Agrotóxicos no Brasil um guia para ação em defesa da vida. Rio de Janeiro: AS-PTA; 2011.

2. Mello C M, Silva LF. Fatores associados à intoxicação por agrotóxicos: estudo transversal com trabalhadores da cafeicultura no sul de Minas Gerais. Epidemiol. Serv. Saúde. 2013; 22(4):609-620.

3. Spadotto CA. [internet] Agrotóxicos no Brasil. [acesso em 2017 abr 12]. Disponível em: http://www.agencia. cnptia.embrapa.br/gestor/agricultura_e_meio_ambiente/arvore/CONTAG01_40_210200792814.html.

4. Faria NMX, Fassa AG, Facchini LA. Intoxicação por agrotóxicos no Brasil: os sistemas oficiais de informação e desafios para realização de estudos epidemio- lógicos. Ciênc. saúde coletiva. 2007 Mar; 12(1):25-38.

5. Santos LDC, Oliveira MFF, Rodrigues MA, et al. Investigação sobre o manejo e aplicação de agrotóxicos pelos agricultores da fazenda Boa Vista, do município de Goioerê-PR e do vilarejo Água Santo Antônio, do município de Janiópolis-PR, 2000. Arq. Apedec. 2001; 5(1):15-21.

6. Soares WL, Porto MF. Uso de agrotóxicos e impactos econômicos sobre a saúde. Rev. Saúde Pública. 2012 Ago; 46(2):209-217.

7. Lara SS, Matos AFF, Neves SMA, et al. Intoxicação aguda por agrotóxicos nos estados do Brasil, 2006 a 2010. Cadernos de Agroecologia. 2015; 10(3):1-5. 
8. Brasil. Ministério da Saúde. Portaria no 104 , de 25 de janeiro de 2011. Define as terminologias adotadas em legislação nacional, conforme o disposto no Regulamento Sanitário Internacional 2005. Diário Oficial [da] República Federativa do Brasil [internet]. 2011 jan 25. [acesso em 2017 dez 19]. Disponível em: http://bvsms.saude.gov.br/bvs/saudelegis/gm/2011/ prt0104_25_01_2011.html.

9. Silva JFA, Gaidecksa JM, Reis ACJ, et al. Prevalência dos casos de intoxicação por agrotóxicos (2007-2010) em São Miguel do Oeste-SC. UEPG. 2011; 17(2):123131.

10. Menck VF. Intoxicação do(a) trabalhador(a) rural por agrotóxicos: (sub)notificação e (in)visibilidade nas políticas públicas [dissertação]. [Limeira]: Universidade Estadual de Campinas; 2016. 149 p.

11. Santos ML. Fatores associados à subnotificação de TB e Aids, durante os anos de 2001 a 2010, a partir do Sinan [dissertação]. [Recife]: Fundação Oswaldo Cruz; 2014. 60 p.

12. Rebelo F, Caldas ED, Heliodoro VO, et al. Intoxicação por agrotóxicos no Distrito Federal, Brasil, de 2004 a 2007 - análise da notificação ao Centro de Informação e Assistência Toxicológica. Ciênc. saúde coletiva. 2011 ago; 16(8):3493-3502.

13. Santos, MI. Manejo de agrotóxicos e seus impactos na saúde dos trabalhadores da agricultura de abacaxi de um assentamento do Tocantins [dissertação]. [Palmas]: Universidade Federal do Tocantins; 2012. 94 p.

14. Bedor CNG, Ramos LO, Pereira PJ, et al. Vulnerabilidades e situações de riscos relacionados ao uso de agrotóxicos na fruticultura irrigada. Rev. bras. epidemiol. [internet] $2009 \mathrm{dez}$; [acesso em 2017 mar 20]; 12(1):39-49. Disponível em: http://www.scielosp.org/ pdf/rbepid/v12nl/05.pdf.

15. Santana VS, Moura MCP, Nogueira FF, et al. Mortalidade por intoxicação ocupacional relacionada a agrotóxicos, 2000-2009, Brasil. Revista de Saúde Pública. 2013 jun; 47(3):598-606.
16. Malaspina FG, Zinilise ML, Bueno PC. Perfil epidemiológico das intoxicações por agrotóxicos no Brasil, no período de 1995 a 2010. Cad. Saude Colet. [internet]. 2011 Nov, [acesso em 2017 mar 20]; 4(19):425434. Disponível em: http://www.cadernos.iesc.ufrj.br/ cadernos/images/csc/2011_4/artigos/csc_vl9n4_425434.pdf.

17. Santos LA. O Impacto das intoxicações causadas por agrotóxicos no município de Garanhuns-PE [internet]. $9^{\circ}$ Congresso Brasileiro de Agroecologia; 2015; Belém: Aba; 2015 [acesso em 2017 mar 20]. Disponível em: http://revistas.aba-agroecologia.org.br/index.php/cad/article/view/19281.

18. Carneiro BV, Castanho DLM, Rosas WP, et al. Notificação Compulsória de Dengue em Hospital terciário militar: análise da vigilância em saúde. Revista de Medicina e Saúde de Brasília, DF [internet]. 2017 jun 2015; 4(2):144-156, jun. 2015 [acesso em 2017 abr 12]. Disponível em: https://portalrevistas.ucb.br/index.php/rmsbr/article/view/5489.

19. Goto DYN. Qualidade dos dados e oportunidade de notificação da dengue no sistema de informação de agravos de notificação (Sinan), Paraná: uma pesquisa avaliativa [dissertação]. [Curitiba]: Universidade Federal do Paraná; 2015. 143 p.

20. Bordoni PHC, Bordoni LS, Silva JM, et al. Utilização do método de captura-recaptura de casos para a melhoria do registro dos acidentes de trabalho fatais em Belo Horizonte, Minas Gerais, 2011. Epidemiol. Serv. Saúde. 2016 jan; 25(1):1-10.

21. Scardoelli MGC, Buriola AA, Oliveira MLF, et al. Intoxicações por agrotóxicos notificadas na $11^{\mathrm{a}}$ regional de saúde do estado do Paraná. Ciência, Cuidado e Saúde. 2011; 10(3):549-555.

Recebido em 11/05/2017

Aprovado em 27/11/2017

Conflito de interesses: inexistente

Suporte financeiro: não houve 